\title{
Members of the Meloidogyne Avirulence Protein Family Contain Multiple Plant Ligand-Like Motifs
}

\author{
William B. Rutter, Tarek Hewezi, Tom R. Maier, Melissa G. Mitchum, \\ Eric L. Davis, Richard S. Hussey, and Thomas J. Baum
}

First, third, and seventh authors: Department of Plant Pathology and Microbiology, Iowa State University, Ames 50011; second author: Department of Plant Sciences, University of Tennessee, Knoxville 37996-4561; fourth author: Division of Plant Sciences and Bond Life Sciences Center, University of Missouri, Columbia 65211; fifth author: Department of Plant Pathology, North Carolina State University, Raleigh 27695; and sixth author: Department of Plant Pathology, University of Georgia, Athens 30602-7274.

Accepted for publication 5 February 2014.

\begin{abstract}
Rutter, W. B., Hewezi, T., Maier, T. R., Mitchum, M. G., Davis, E. L., Hussey, R. S., and Baum, T. J. 2014. Members of the Meloidogyne avirulence protein family contain multiple plant ligand-like motifs. Phytopathology 104:879-885.

Sedentary plant-parasitic nematodes engage in complex interactions with their host plants by secreting effector proteins. Some effectors of both root-knot nematodes (Meloidogyne spp.) and cyst nematodes (Heterodera and Globodera spp.) mimic plant ligand proteins. Most prominently, cyst nematodes secrete effectors that mimic plant CLAVATA3/ESR-related (CLE) ligand proteins. However, only cyst nematodes have been shown to secrete such effectors and to utilize CLE ligand mimicry in their interactions with host plants. Here, we document the presence of ligand-like motifs in bona fide root-knot nematode

nematodes. We have identified multiple tandem CLE-like motifs conserved within the previously identified Meloidogyne avirulence protein (MAP) family that are secreted from root-knot nematodes and have been shown to function in planta. By searching all 12 MAP family members from multiple Meloidogyne spp., we identified 43 repetitive CLE-like motifs composing 14 unique variants. At least one CLE-like motif was conserved in each MAP family member. Furthermore, we documented the presence of other conserved sequences that resemble the variable domains described in Heterodera and Globodera CLE effectors. These findings document that root-knot nematodes appear to use CLE ligand mimicry and point toward a common host node targeted by two evolutionarily diverse groups of nematodes. As a consequence, it is likely that CLE signaling pathways are important in other phytonematode pathosystems as well.
\end{abstract} effectors that are most similar to CLE peptides from plants and cyst
Cell-to-cell communication through small secreted peptides has emerged as an important signaling mechanism in plant growth and development. One important gene family, the CLAVATA/ ESR-related (CLE) gene family, encodes a large and diverse group of small signaling peptides found ubiquitously in plants $(8,24,31)$. The Arabidopsis genome alone encodes 32 known CLE genes, which share 14 similar amino acid CLE motifs. These motifs are processed into 12- or 13-amino-acid peptides that are secreted as ligands for receptor-like kinases (RLKs) that subsequently incite developmental changes within plant cells $(13,21)$. The nature of the developmental changes enacted by these small peptides varies depending on their amino acid sequence and how they are processed, as well as the expression patterns of the CLE genes within the plant $(22,36,44)$. The best-studied CLE protein, CLAVATA3, modulates stem-cell proliferation in the shoot and root apical meristems $(13,21)$, while other CLE proteins have been shown to activate developmental pathways in the plant vasculature $(21,24,25)$. Other CLE peptides have even been shown to function in both the apical meristems and the vasculature (44). Although it has been established that CLE signaling influences plant growth and development, the exact roles that most CLE genes play in modulating these processes remain only partially understood.

Corresponding author: T. J. Baum; E-mail address: tbaum@iastate.edu

http://dx.doi.org/10.1094/PHYTO-11-13-0326-R

(c) 2014 The American Phytopathological Society
In an intriguing example of co-evolution of plants and parasites, it has become evident over the last decade that cyst nematodes (Heterodera and Globodera spp.), which are important sedentary plant-parasitic roundworms, secrete CLE ligand mimics as effector proteins into their host plants $(28,30,33,40,42,43)$. Interestingly, sedentary plant-parasitic nematodes developmentally reprogram plant cells to induce the formation of novel plant cell types that serve as feeding cells for the nematodes. In the case of cyst nematode parasitism, these feeding cells fuse and form a multinucleated syncytium (15). Similar to endogenous CLE proteins, cyst nematode CLE effectors are processed into functional 12- and 13-amino-acid peptides after being secreted in planta and have been shown to enact plant developmental changes that facilitate parasitism. $(28,34,41,43)$. Indeed, certain cyst nematode CLE effector genes can rescue Arabidopsis CLAVATA3 mutant phenotypes $(28,40,41,43)$, suggesting that these effectors can mimic CLE-dependent signaling in planta.

All sedentary plant-parasitic nematodes deliver effectors into their host plant tissues. These proteins alter normal host development to induce the formation of highly specialized feeding cells $(3,18,29)$. The ability to engage in this type of sophisticated plantparasite interaction has evolved in several groups of nematodes, the most prominent of which are the root-knot nematodes (RKNs) (Meloidogyne spp.), a large assembly of taxa that contains the world's most notorious and damaging plant-parasitic nematodes. Similar to cyst nematodes, RKNs induce the formation of modified feeding cells (called giant cells) within the plant, although with etiology and structure distinct from that of the syncytia induced by cyst nematodes. Despite the analogous parasitic strategies of root-knot and cyst nematodes, only a few common effec- 
tors have been shown to be secreted by both groups $(14,17,20)$. Sequences that resemble plant ligands have recently been reported from RKNs. One such sequence (named 16D10) was shown to code for a protein with function in nematode-plant interactions; however, its mode of action is different from that of CLE peptides (19). Still other such sequences have been identified but have not been functionally characterized or experimentally implicated in the plant-parasite interaction $(6,38)$. Furthermore, these RKN sequences consist only of small coding sequences composed of a secretion signal peptide and a putative signaling peptide, whereas cyst nematodes produce larger and more complex CLE effectors that are processed and transported post-delivery into the plant cell.

Here, we report that the previously described Meloidogyne avirulence protein (MAP) family of proteins secreted from RKNs $(7,37)$ contains plant ligand-like motifs that have gone undetected. Furthermore, we have found that these motifs resemble the bioactive CLE peptides from both plants and cyst nematodes, and are embedded within larger and more complex sequences reminiscent of the variable domains (VDs) found in CLE effectors secreted by both Heterodera and Globodera spp. These findings suggest that RKNs may use ligand-mimicking effectors to tap into plant signaling pathways in a manner similar to cyst nematodes.

\section{MATERIALS AND METHODS}

In situ hybridizations. Specific forward and reverse primers were designed to amplify an amplicon of 150 to $300 \mathrm{bp}$ from cDNA pools generated from mixed stages parasitic stages of Meloidogyne incognita. This amplicon was used as a template in a unidirectional polymerase chain reaction (PCR) to produce single-stranded sense and anti-sense digoxigenin (DIG)-labeled probes for each candidate effector transcript. Unidirectional PCRs were performed in $25 \mu \mathrm{l}$ volumes using a DIG-nucleotide labeling kit (Roche, Mannheim, Germany). In situ hybridizations were performed on mixed parasitic stages of $M$. incognita, as previously described (11). Established parasitic populations of nematodes were extracted from tomato roots (Lycopersicon esculentum 'Rutgers') by maceration of the infected tissue followed by progressive sieving, as previously described (12). These parasitic stages were supplemented with freshly hatched preparasitic second-stage juveniles (J2s) of $M$. incognita. Mixedstage nematodes were fixed in a $2 \%$ formaldehyde solution. Fixed nematodes were permeabilized by hand cutting with a razorblade on a glass slide in combination with a partial proteinase-K digestion $(20 \mathrm{mg} / \mathrm{ml}, 30 \mathrm{~min}$ at room temperature). DIG-labeled probes were hybridized to permeabilized tissue overnight at $50^{\circ} \mathrm{C}$. Hybridized probes within the nematode were detected using an

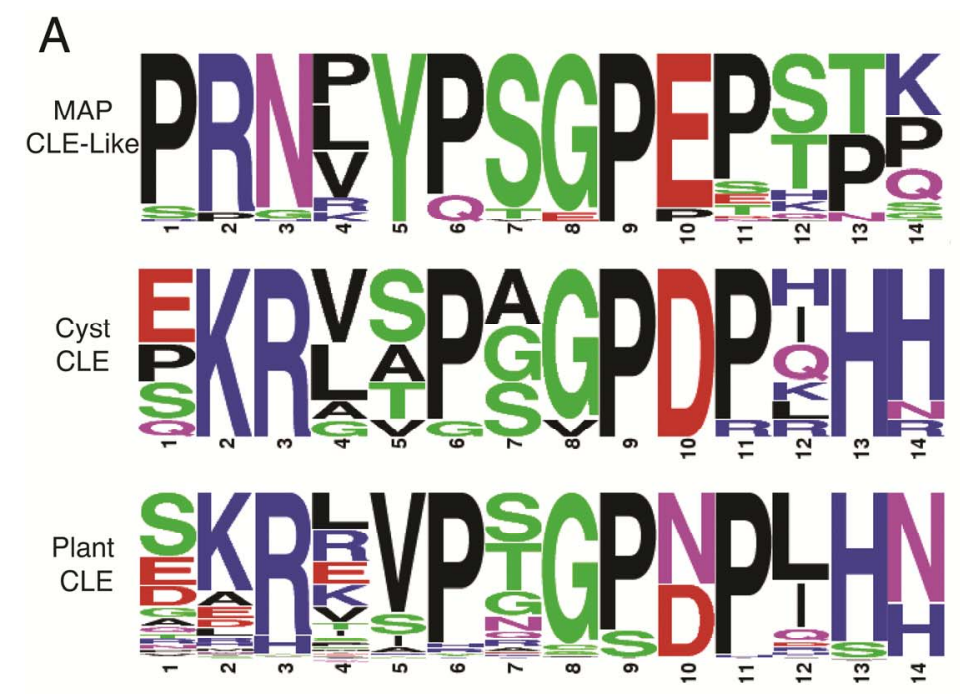

B

Invariant Residues
MAP.V1
MAP.V2
MAP.V3
MAP.V4
MAP.V5
MAP.V6
MAP.V7
MAP.V8
MAP.V9
MAP.V10
MAP.V11
MAP.V12
MAP.V13
MAP.V14
M.inc.16D10
H.g1ycines.CLE1
H.g1ycines.CLE2
H.schachtii.CLE1
H.schachtii.CLE2
G.rostochiensis.CLE1.M1
G.rostochiensis.CLE1.M2
G.rostochiensis.CLE4.M1
G.rostochiensis.CLE4.M3
G.rostochiensis.CLE4.M2
G.max.CLE23
T.aestivum.CLE29
M.truncatula.CLE39
A.thaliana.CLE42
A.thaliana.CLE45
0.sativia.CLE85
O.sativia.CLE93
O.sativia.CLE106
O.sativia.CLE110
P.trichocarpa.CLE129
P.trichocarpa.CLE134
Z.mays.CLE143
P.vulagaris.CLE176

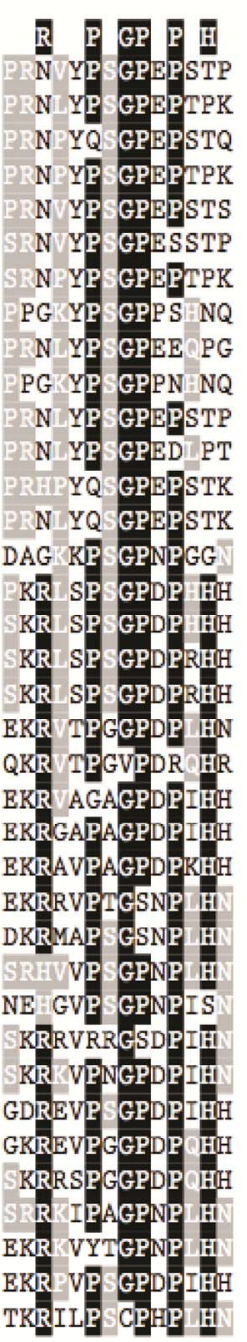

Fig. 1. Comparison of CLAVATA3/ESR-related (CLE)-like motifs in the Meloidogyne avirulence protein (MAP) family to known CLE motifs in cyst nematode and plant proteins A, Comparison of the amino acid frequency in the 43 CLE-like motifs identified in MAPs with the amino acid frequencies within 9 known CLE motifs from cyst nematodes and 179 CLE motifs from plants. B, Sequence alignment of the CLE-like motifs identified in the MAPs (MAP.V1-14) (black) and those identified in cyst nematodes (blue), plants (green), and the 16D10 effector protein from Meloidogyne incognita. Residues that match invariant residues are highlighted in black and other residues found in both CLEs and MAPs are highlighted in gray. 
anti-DIG antibody conjugated to alkaline phosphatase and its substrate. Samples were then visualized using a Zeiss Axiovert 100 inverted light microscope.

Motif detection. The amino acid sequence of the 12 known MAP family members-Minc00365, Minc10365, Minc10366, Minc00158, Minc00344, and Minc04584 protein sequences annotated within the $M$. incognita genome (1) as well as CAQ63470.1, CAC27774.1, CAP59537.1, CAP59538.1, CAP59536.1, and CAP59535.1-were searched alongside CLE effector proteins from Heterodera spp. (AEA06591.1, AEA06592.1, ACT32610.1, and ACT32609.1) and Globodera spp. (ACY70449.1-ACY70456.1) using the MEME online software suite (5). The search windows were incrementally adjusted to obtain the maximum regions of identity between cyst nematode CLE effectors and the MAPs. All nonredundant iterations of the identified motifs from both MAPs and CLE effectors were aligned using the ClustalW version 2.0 (27) online server for visual comparison of the degree of amino acid conservation. Sequence frequency logos were generated using WebLogo (9) for each motif using every identified occurrence to assess the frequency of each residue within each identified motif.

\section{RESULTS}

We are continuously mining $M$. incognita sequence data to confirm new effector identities. While scrutinizing a group of newly confirmed $M$. incognita effector candidates (unpublished data), we found that two proteins (designated Minc04584 and Minc00344 by the $M$. incognita genome sequencing consortium) $(1,2)$ contained repetitive 14 -amino-acid motifs with sequence similarities to known CLE peptides from both plants and cyst nematode species. Interestingly, Minc04584 and Minc00344 belong to the MAP gene family containing the previously reported MAP-1 secreted from $M$. incognita $(7,37)$. MAP-1 is the type member of this gene family and was identified as being differ-

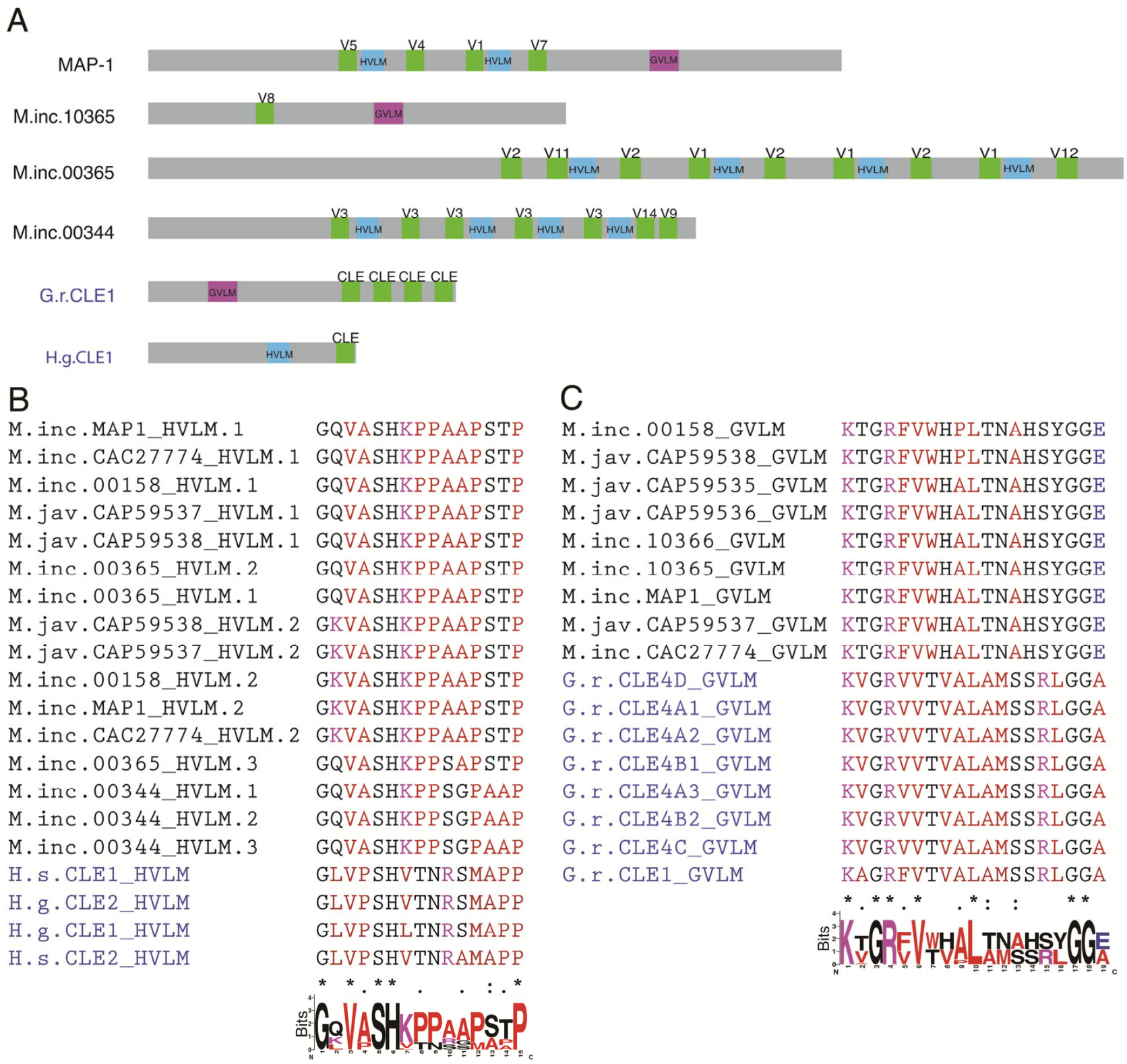

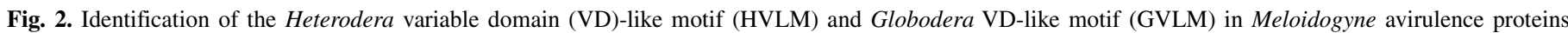
(MAPs) and their distribution within MAP family proteins. A, Scaled representation of the relative locations of HVLM (blue), GVDLM (purple), and CLAVATA3/ESR-related (CLE)-like domains (green) within MAPs and cyst nematode CLE effectors. B, Sequence alignment of all HVLMs from seven MAPs and those found in the CLE effectors of Heterodera spp. (blue) along with a sequence logo highlighting the conserved residues among all motifs. C, Sequence alignment of all GVLMs from nine MAPs and those found in the CLE effectors of Globodera spp. (blue) along with a sequence logo highlighting the conserved residues among all motifs. 
entially present between virulent and avirulent lines of $M$. incognita (35). Although MAPs are thought to function in the interaction between $M$. incognita and its plant hosts, their mode of action remains unknown. Furthermore, whereas multiple members of this gene family have been reported in multiple Meloidogyne spp., the presence of CLE-like repeat domains within the known MAPs had not been detected.

The detection of repeat CLE motifs in our two newly confirmed MAP-family effectors prompted us to investigate the extent to which CLE-like motifs are conserved within the reported MAP family. Previous studies have identified eight MAP family members from $M$. incognita (Minc00365, Minc10365, Minc10366, Minc00158, Minc00344, Minc04584, MAP-1.2, and gb|CAC27774.1) (7,35). Our analysis was extended to also include four MAPs from $M$. javanica, which were available in the National Center for Biotechnology Information database (gb|CAP59537.1, CAP59538.1, CAP59536.1, and CAP59535.1). We also included the previously reported Meloidogyne effector protein (16D10) that appears to have a single conserved CLE domain, although its function has been shown to be very different from that of the cyst nematode CLE effectors (19). Using the MEME software suite (5), we screened all of the 12 Meloidogyne MAPs and 16D10 for the presence of common motifs. Using a 12-amino-acid search window, the MEME software identified similar CLE-like motifs conserved in all of the MAP family proteins but not in 16D10 (Fig. 1A). This motif was repeated a variable number of times within each of the MAP family members. Although Minc10365 contained only a single CLE-like motif, nine CLE-like repeats were found in Minc00365. In all, we discovered a total of 43 separate CLE-like motifs among the 12 MAPs. Many of these motifs were identical, even when compared between the proteins from $M$. javanica and $M$. incognita. After removing redundant copies, 14 unique CLE-like variants were identified and were named MAP.V1-MAP.V14 (Fig. 1B).

CLE motifs are inherently hard to identify. The 178 known CLE proteins from plants can only be grouped by the common 14-amino-acid CLE motif and, within this motif, there is no single amino acid that is conserved throughout the entire gene family. Indeed, studies of plant CLE motifs have identified only six well-conserved residues (termed invariant residues in the literature) that are considered hallmarks of the CLE family (31). Because of the central location and relatively high conservation of the amino acid glycine within the CLE motif, this residue is used as a reference point for locating the other invariant residues $\left(\mathrm{R}_{-5}, \mathrm{P}_{-2}, \mathrm{G}_{0}, \mathrm{P}_{+1}, \mathrm{P}_{+3}, \mathrm{H}_{+5}\right)$.

To quantify the similarities between the MAP CLE-like motifs and known CLE peptides, MAP.V1-V14 were aligned with known CLE motifs from plants as well as from cyst nematode species (Fig. 1B). Examination of the alignment revealed that five of the six invariant residues found in CLEs $\left(\mathrm{R}_{-5}, \mathrm{P}_{-2}, \mathrm{G}_{0}, \mathrm{P}_{+1}, \mathrm{P}_{+3}\right.$, are also present in the MAP CLE-like motifs to varying degrees. Furthermore, all 43 identified CLE-like motifs contain at least three of the six invariant residues. The central highly conserved glycine $\left(\mathrm{G}_{0}\right)$ and proline $\left(\mathrm{P}_{+1}\right)$ in plant CLEs are also present in all 43 CLE-like motifs in the MAPs, and 35 of the CLE-like motifs also contain the invariant proline $\left(\mathrm{P}_{-2}\right)$. Interestingly, the invariant arginine $\left(\mathrm{R}_{-5}\right)$ of most plant CLEs is consistently found one residue back in 40 of the MAP motifs (i.e., $R_{-6}$ ). This is consistent with the positioning of arginine $\left(\mathrm{R}_{-6}\right)$ in CLE39 from Medicago truncatula and several other plant CLEs (31). The invariant histidine $\left(\mathrm{H}_{+5}\right)$ is the only residue that is not present in any of the Meloidogyne CLE-like motifs. In total, 27 of the motifs in the MAPs contain five of the six invariant CLE residues (Fig. 1B). This alignment shows that sequence divergence within MAP CLE-like motifs resembles the natural variation found in known CLE motifs from plants and cyst nematodes. The presence of the prolines $\left(\mathrm{P}_{-2}\right.$ and $\left.\mathrm{P}_{+1}\right)$ is of particular significance. Both of these residues have been shown to be hydroxylated or arabinosylated in planta, and these post-translational modifications have been shown to enhance the interactions between CLE peptides and their cognate RLKs $(26,32)$.

In addition to the CLE domains, the CLE effector proteins secreted from cyst nematodes also contain VDs, which share little or no sequence homology with any plant CLE proteins. Despite their lack of sequence conservation, VDs are documented as having regulatory functions that are required for the cyst nematode CLE effectors to function in planta. Indeed, previous research has shown that VDs function in trafficking of CLE effectors to the host apoplast and processing of mature CLE peptides, and may also determine host specificity $(16,41)$. In the root-knot MAPs scrutinized in this study, we observed that there are additional repetitive sequence motifs outside the CLE-like domains where the amino acid sequence tended to be less well conserved. Therefore, we searched the MAPs and 16D10 for the presence of VDlike sequences, which could corroborate the hypothesis that Meloidogyne MAP effectors function in a manner similar to known cyst nematode CLE effectors. We identified two separate MAP family motifs that showed sequence similarity with the VDs of cyst nematodes, whereas no such domains are present in 16D10. Curiously, one MAP motif was found only in Heterodera CLE protein VDs while the other one was found only in Globodera CLE VDs. We named these two conserved motifs Heterodera VD-like motif (HVLM) and Globodera VD-like motif (GVLM) respectively. The HVLM is a stretch of 15 amino acids (G78-P92 within Heterodera CLE effectors) in the VDs of all reported Heterodera CLE effectors. HVLM occurs multiple times within 7 of the 12 MAPs searched (Minc00365, Minc00158, Minc00344, MAP-1.2, CAC27774.1, CAP59537.1, and CAP59538.1) and was interspersed between the CLE-like motifs (Fig. 2A). Sequence alignment of the HVLMs from MAPs with those found in Heterodera VDs revealed that 5 of the 15 residues are perfectly conserved and an additional five residues have conserved properties (Fig. 2B) ( $\leq 0.5$ Gonnet PAM 250 matrix).

GVLM is a 19-amino-acid stretch that occurs in the VDs of Globodera rostochiensis CLE effectors. We found GVLM directly downstream of the CLE-like repeats in 9 of the 12 MAPs (Minc10365, Minc10366, Minc00158, MAP-1.2, CAC27774.1, CAP59537.1, CAP59538.1, CAP59536.1, and CAP59535.1) (Fig. 2A). When comparing the GVLMs from the MAPs with those from the G. rostochiensis VDs, we found that seven GVLM residues are perfectly conserved and an additional five residues have conserved properties (Fig. 2C) ( $\leq 0.5$ Gonnet PAM 250 matrix).

Of the 12 MAPs, only MAP-1 from Meloidogyne incognita and one MAP from $M$. javanica have been subjected to limited functional characterization. MAP-1 has been shown to be secreted from infective nematodes into plant tissues $(35,39)$. Surprisingly, in $M$. incognita, MAP-1 was shown to be secreted from the amphids, chemosensory organs in the nematode head region $(35,39)$, whereas the $M$. javanica gene was shown to be specifically expressed in the subventral esophageal glands (4). These esophageal gland cells are the main sources of secreted effector proteins from both root-knot and cyst nematodes $(14,20)$. To determine where the other members of this protein family are expressed, we performed in situ hybridization on mixed developmental stages of $M$. incognita juveniles using probes specific for three MAP family members (Minc00158, Minc00344, and Minc04584). We were able to localize expression of these three MAP family members specifically to the subventral glands of J2 nematodes (Fig. 3). Given the specific expression in the esophageal gland cells, the MAP family proteins are likely to be secreted through the nematode's stylet into host plant cells during parasitism.

\section{DISCUSSION}

Given the fundamental roles of CLE signaling in plant development and discovery of functional secreted CLEs in cyst 
nematodes (30), it would not be surprising to find that RKNs have also evolved a mechanism to co-opt CLE-dependent signaling pathways into their mode of parasitism. Our discovery of CLElike motifs embedded within MAPs and confirmation of their expression in RKN esophageal gland secretory cells suggests that this may be the case. Meloidogyne spp. infect a wide range of host plants, and the ubiquitous presence of CLE signaling proteins in diverse plant species makes these proteins an ever-present target for mimicry. Modulating CLE signaling in infected root cells could help to establish feeding sites. Though the exact functional role of the MAP CLE-like motifs will require further investigation, it is clear that MAPs are playing an important role in facilitating parasitism. The secretion of MAPs from both the amphids $(35,39)$ and the subventral glands (4, this study) of infective J2s suggests that these proteins may be involved in the early recognition stage between the host plants and the nematode and lends credibility to the hypothesis that these proteins are acting as ligand mimics binding extracellular host receptors. Indeed, immunodetection of MAP-1 showed that it accumulates along the giantcell wall and root cell apoplast at RKN infection sites (39).

The repetitive region of the MAP-1 gene, which contains the CLE-like motifs, was recently amplified from 13 Meloidogyne spp. out of the 21 that were searched (37). These CLE-like regions within MAP-1 are nearly devoid of mutations between species, indicating that they have a virulence function that has enhanced parasite fitness and enforced strong purifying selection to conserve these sequences. Furthermore, the presence of functional and diverse CLE mimics in cyst nematodes (30) is a testament to the functional importance that the CLE signaling pathway can have in plant parasitism.

Though the majority of CLE proteins from plants contain a single CLE motif on their C terminus, several have been documented as having multiple tandem CLE repeats, similar to the Meloidogyne MAPs (31). In nematodes, CLE effector proteins secreted by the potato cyst nematode ( $G$. rostochiensis) contain CLE motifs that are organized in tandem repeats, and these effectors have recently been shown to be processed into functional CLE peptides in planta (16). It is plausible that the tandem CLElike motifs seen in the MAP family proteins could be processed in a similar manner, in which individual motifs are cleaved and secreted to interact with cognate extracellular RLKs. The existence of multiple nonidentical CLE-like motifs in MAPs may reflect an evolutionary adaption to enable RKNs to infect a wide range of host species. In this context, one can expect that such motifs can function by mimicking host factors more effectively in one particular host plant than in others.

In contrast to the tandem CLE motifs found in G. rostochiensis effectors, the CLE-like motifs in the MAPs have additional repetitive sequences between each motif. It is conceivable that this additional sequence could have functions similar to the VDs found in cyst nematode and plant CLE proteins. The VDs of CLE proteins are thought to play roles in the processing of active CLE peptides and have been shown to effect host specificity in cyst nematode CLE effectors $(23,41)$. Consistent with this line of evidence, the HVLM was identified within the MAPs that have multiple CLE-like motifs and is interspersed between individual CLE-like motifs (Fig. 2A). This type of arrangement could allow separate MAP CLEs to have their own processing signal. Although there is no direct evidence to prove that the HVLMs in the MAPs function in CLE-like processing, the fact that they are closely associated with the CLE-like motifs and share sequence homology with the VD region of cyst nematode CLEs (41) suggests that they may have regulatory roles.

The presence of CLE mimicking effectors in both cyst nematode and RKN species begs the question: how did these genes arise? Outside of the three motifs, there is very little sequence conservation between the flanking protein sequences from Heterodera and Globodera spp. and the MAPs from Meloidogyne. This suggests that these CLE-like motifs may well have arisen through convergent evolution, where the nematodes independently evolved features similar to host factors. Another intriguing possibility is that these CLE proteins were acquired through horizontal gene transfer (HGT) from host genomes. A recent study identified multiple HGT events that have taken place in plant-parasitic nematodes and identified a large repertoire of cell-wall-degrading enzymes that were acquired from bacteria (10). Indeed, this same study showed that some of the MAPs have regions that have similarities with expansins from fungi (10), though no expansin activity has yet been reported. With the nematode's propensity for HGT and the similarities that MAPs share with plant proteins, it is possible to speculate that CLE-mimicking effectors could represent yet another instance of HGT in nematodes.

The presence of plant ligand-mimicking effectors in these diverse nematode species also raises the question of how these effectors act to facilitate nematode parasitism. Because CLE effectors from cyst nematodes are known to effect plant development, it has been hypothesized that these effectors may assist the parasite by initiating the essential and drastic developmental changes that form the nematode's feeding site (30). Indeed, the feeding sites produced by both cyst nematodes and RKNs are the result of drastic changes in the normal plant growth and development initiated by the parasite $(15,18,29)$. However, the developmental changes initiated by endogenous plant CLEs are diverse and can even vary depending on their spatial and temporal expression patterns within the plant (44). This variability makes it difficult to predict which exact developmental changes the nematode ligand mimics are initiating during feeding site formation. Further study is needed to elucidate the developmental effects of both endogenous plant CLEs as well as the CLE-mimicking effectors secreted by nematode parasites, before we can fully understand their role in the nematode-plant interaction.

In summary, CLE ligand mimics are known to be secreted by cyst nematodes to facilitate successful infection of their host plants (30). Although ligand-like sequences previously have been predicted in RKN genomes, here, we have identified CLE-like motifs as well as adjacent VDs embedded within the MAP family proteins secreted from RKNs, a family of proteins that was previously known to be critical to the host-parasite interaction (7). We have shown that several members of this gene family are expressed in the esophageal gland cells, which produce many known nematode effectors, including the CLE mimics found in

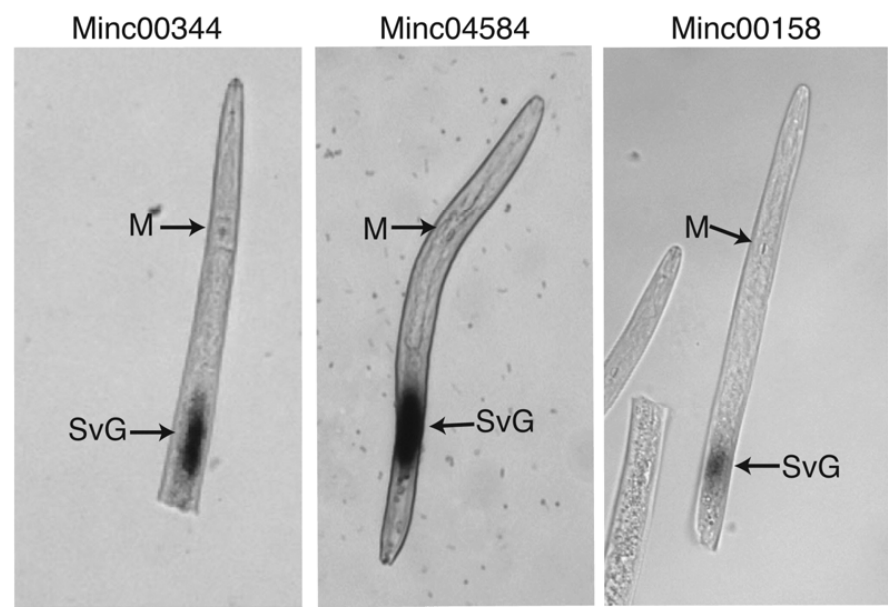

Fig. 3. In situ hybridization to transcripts from three Meloidogyne avirulence protein (MAP) family members. Labeled anti-sense probes specific for three separate MAP family members (Minc00344, Minc0458, and Minc00158) were used to localize the accumulation of their respective transcripts within Meloidogyne incognita. All three MAP family members showed specific expression within the subventral gland cells (SvG), which are located posteriorly relative to the metacorpus $(\mathrm{M})$. 
cyst nematodes. With the evidence at hand, we hypothesize that the MAP family of proteins may function as CLE-mimics in some capacity, perhaps as peptides processed in planta. The presence of CLE effector peptides in both cyst nematodes and RKNs highlights a common host node that is targeted by two evolutionarily diverse groups of nematodes and may be present in other phytonematode pathosystems as well.

\section{ACKNOWLEDGMENTS}

This is a Journal Paper of the Iowa Agriculture and Home Economics Experiment Station, Ames, supported by Hatch Act and State of Iowa funds. This work was funded by a grant (2280) from the United Soybean Board.

\section{LITERATURE CITED}

1. Abad, P. 2009. Meloidogyne incognita resources. INRA, Sophia-Antipolis, France.

2. Abad, P., Gouzy, J., Aury, J. M., Castagnone-Sereno, P., Danchin, E. G. J., Deleury, E., Perfus-Barbeoch, L., Anthouard, V., Artiguenave, F., Blok, V. C., Caillaud, M. C., Coutinho, P. M., Dasilva, C., De Luca, F., Deau, F., Esquibet, M., Flutre, T., Goldstone, J. V., Hamamouch, N., Hewezi, T., Jaillon, O., Jubin, C., Leonetti, P., Magliano, M., Maier, T. R., Markov, G. V., McVeigh, P., Pesole, G., Poulain, J., Robinson-Rechavi, M., Sallet, E., Segurens, B., Steinbach, D., Tytgat, T., Ugarte, E., van Ghelder, C., Veronico, P., Baum, T. J., Blaxter, M., Bleve-Zacheo, T., Davis, E. L., Ewbank, J. J., Favery, B., Grenier, E., Henrissat, B., Jones, J. T., Laudet, V., Maule, A. G., Quesneville, H., Rosso, M. N., Schiex, T., Smant, G., Weissenbach, J., and Wincker, P. 2008. Genome sequence of the metazoan plant-parasitic nematode Meloidogyne incognita. Nat. Biotechnol. 26:909-915. Online publication. doi:10.1038/Nbt.1482

3. Abad, P., and Williamson, V. M. 2010. Plant nematode interaction: a sophisticated dialogue. Pages 147-192 in: Advances in Botanical Research, Vol. 53. Elsevier Inc., Philadelphia, PA.

4. Adam, M. A. M., Phillips, M. S., Tzortzakakis, E. A., and Blok, V. C. 2009. Characterisation of mjap genes encoding novel secreted proteins from the root-knot nematode, Meloidogyne javanica. Nematology 11:253265. Online publication. doi:10.1163/156854109x429583

5. Bailey, T. L., Boden, M., Buske, F. A., Frith, M., Grant, C. E., Clementi, L., Ren, J. Y., Li, W. W., and Noble, W. S. 2009. MEME SUITE: tools for motif discovery and searching. Nucleic Acids Res. 37:W202-W208. Online publication. doi:10.1093/Nar/Gkp335

6. Bird, D. M., and DiGennaro, P. M. 2012. Nematode communication with plants is surprisingly complex and multidimensional. Pages 213-230 In: Biocommunication of Plants. G. Witzany and F. Baluska, eds. SpringerVerlag, Berlin, Germany.

7. Castagnone-Sereno, P., Semblat, J. P., and Castagnone, C. 2009. Modular architecture and evolution of the map-1 gene family in the root-knot nematode Meloidogyne incognita. Mol. Genet. Genomics 282:547-554. Online publication. doi:10.1007/S00438-009-0487-X

8. Cock, J. M., and McCormick, S. 2001. A large family of genes that share homology with CLAVATA3. Plant Physiol. 126:939-942.

9. Crooks, G. E., Hon, G., Chandonia, J. M., and Brenner, S. E. 2004. WebLogo: a sequence logo generator. Genome Res. 14:1188-1190. Online publication. doi:10.1101/gr.849004

10. Danchin, E. G. J., Rosso, M. N., Vieira, P., de Almeida-Engler, J., Coutinho, P. M., Henrissat, B., and Abad, P. 2010. Multiple lateral gene transfers and duplications have promoted plant parasitism ability in nematodes. Proc. Natl. Acad. Sci. USA 107:17651-17656. Online publication. doi:10.1073/pnas.1008486107

11. de Boer, J. M., Yan, Y., Smant, G., Davis, E. L., and Baum, T. J. 1998. Insitu hybridization to messenger RNA in Heterodera glycines. J. Nematol. 30:309-312.

12. de Boer, J. M., Yan, Y., Wang, X., Smant, G., Hussey, R. S., Davis, E. L., and Baum, T. J. 1999. Developmental expression of secretory beta-1,4endoglucanases in the subventral esophageal glands of Heterodera glycines. Mol. Plant-Microbe Interact. 12:663-669. Online publication. doi:10.1094/MPMI.1999.12.8.663

13. Fiers, M., Golemiec, E., van der Schors, R., van der Geest, L., Li, K. W., Stiekema, W. J., and Liu, C. M. 2006. The CLAVATA3/ESR motif of CLAVATA3 is functionally independent from the nonconserved flanking sequences. Plant Physiol. 141:1284-1292. Online publication. doi: pp.106.080671 [pii] 10.1104/pp.106.080671

14. Gao, B. L., Allen, R., Maier, T., Davis, E. L., Baum, T. J., and Hussey, R. S. 2001. Identification of putative parasitism genes expressed in the esophageal gland cells of the soybean cyst nematode Heterodera glycines. Mol. Plant-Microbe Interact. 14:1247-1254.
15. Golinowski, W., Sobczak, M., Kurek, W., and Grymaszewska, G. 1997. The structure of syncytia. In: Cellular and Molecular Aspects of PlantNematode Interactions, Vol. 10. C. Fenoll, F. M. W. Grundler, and S. A. Ohl, eds. Kluwer Academic Publishers, Dordrecht, The Netherlands.

16. Guo, Y. F., Ni, J., Denver, R., Wang, X. H., and Clark, S. E. 2011. Mechanisms of molecular mimicry of plant CLE peptide ligands by the parasitic nematode Globodera rostochiensis. Plant Physiol. 157:476-484. Online publication. doi:10.1104/Pp.111.180554

17. Hassan, S., Behm, C. A., and Mathesius, U. 2010. Effectors of plant parasitic nematodes that re-program root cell development. Funct. Plant Biol. 37:933-942. Online publication. doi:10.1071/Fp10112

18. Hewezi, T., and Baum, T. 2012. Manipulation of plant cells by cyst and root-knot nematode effectors. Mol. Plant-Microbe Interact. Online publication. doi:10.1094/MPMI-05-12-0106-FI

19. Huang, G. Z., Dong, R. H., Allen, R., Davis, E. L., Baum, T. J., and Hussey, R. S. 2006. A root-knot nematode secretory peptide functions as a ligand for a plant transcription factor. Mol. Plant-Microbe Interact. 19:463-470. Online publication. doi:10.1094/mpmi-19-0463

20. Huang, G. Z., Gao, B. L., Maier, T., Allen, R., Davis, E. L., Baum, T. J., and Hussey, R. S. 2003. A profile of putative parasitism genes expressed in the esophageal gland cells of the root-knot nematode Meloidogyne incognita. Mol. Plant-Microbe Interact. 16:376-381.

21. Ito, Y., Nakanomyo, I., Motose, H., Iwamoto, K., Sawa, S., Dohmae, N., and Fukuda, H. 2006. Dodeca-CLE peptides as suppressors of plant stem cell differentiation. Science 313:842-845. Online publication. doi: 10.1126/science. 1128436

22. Jun, J., Fiume, E., Roeder, A. H. K., Meng, L., Sharma, V. K., Osmont, K. S., Baker, C., Ha, C. M., Meyerowitz, E. M., Feldman, L. J., and Fletcher, J. C. 2010. Comprehensive analysis of CLE polypeptide signaling gene expression and overexpression activity in Arabidopsis. Plant Physiol. 154:1721-1736. Online publication. doi:10.1104/Pp.110.163683

23. Jun, J. H., Fiume, E., and Fletcher, J. C. 2008. The CLE family of plant polypeptide signaling molecules. Cell. Mol. Life Sci. 65:743-755. Online publication. doi:10.1007/S00018-007-7411-5

24. Katsir, L., Davies, K. A., Bergmann, D. C., and Laux, T. 2011. Peptide signaling in plant development. Curr. Biol. 21:R356-R364. Online publication. doi:10.1016/J.Cub.2011.03.012

25. Kinoshita, A., Nakamura, Y., Sasaki, E., Kyozuka, J., Fukuda, H., and Sawa, S. 2007. Gain-of-function phenotypes of chemically synthetic CLAVATA3/ESR-related (CLE) peptides in Arabidopsis thaliana and Oryza sativa. Plant Cell Physiol. 48:1821-1825. Online publication. doi:10.1093/pcp/pcm154

26. Kondo, T., Sawa, S., Kinoshita, A., Mizuno, S., Kakimoto, T., Fukuda, H., and Sakagami, Y. 2006. A plant peptide encoded by CLV3 identified by in situ MALDI-TOF MS analysis. Science 313:845-848. Online publication. doi:10.1126/Science.1128439

27. Larkin, M. A., Blackshields, G., Brown, N. P., Chenna, R., McGettigan, P. A., McWilliam, H., Valentin, F., Wallace, I. M., Wilm, A., Lopez, R., Thompson, J. D., Gibson, T. J., and Higgins, D. G. 2007. Clustal W and Clustal X version 2.0. Bioinformatics 23:2947-2948. Online publication. doi:btm404 [pii]10.1093/bioinformatics/btm404

28. Lu, S. W., Chen, S. Y., Wang, J. Y., Yu, H., Chronis, D., Mitchum, M. G., and Wang, X. H. 2009. Structural and functional diversity of CLAVATA3/ ESR (CLE)-like genes from the potato cyst nematode Globodera rostochiensis. Mol. Plant-Microbe Interact. 22:1128-1142. Online publication. doi:10.1094/Mpmi-22-9-1128

29. Mitchum, M. G., Hussey, R. S., Baum, T. J., Wang, X., Elling, A. A., Wubben, M., and Davis, E. L. 2013. Nematode effector proteins: an emerging paradigm of parasitism. New Phytol. Online publication. doi:10.1111/nph.12323

30. Mitchum, M. G., Wang, X., Wang, J., and Davis, E. L. 2012. Role of nematode peptides and other small molecules in plant parasitism. Annu. Rev. Phytopathol. 50:175-195. Online publication. doi:10.1146/annurevphyto-081211-173008

31. Oelkers, K., Goffard, N., Weiller, G. F., Gresshoff, P. M., Mathesius, U., and Frickey, T. 2008. Bioinformatic analysis of the CLE signaling peptide family. BMC Plant Biol. 8. Online publication. doi:10.1186/1471-2229-8-1

32. Ohyama, K., Shinohara, H., Ogawa-Ohnishi, M., and Matsubayashi, Y. 2009. A glycopeptide regulating stem cell fate in Arabidopsis thaliana. Nat. Chem. Biol. 5:578-580. Online publication. doi:10.1038/nchembio.182

33. Olsen, A. N., and Skriver, K. 2003. Ligand mimicry? Plant-parasitic nematode polypeptide with similarity to CLAVATA3. Trends Plant Sci. 8:55-57. Online publication. doi:S1360138503000037

34. Replogle, A., Wang, J., Bleckmann, A., Hussey, R. S., Baum, T. J., Sawa, S., Davis, E. L., Wang, X., Simon, R., and Mitchum, M. G. 2011. Nematode CLE signaling in Arabidopsis requires CLAVATA2 and CORYNE. Plant J. 65:430-440. Online publication. doi:10.1111/j.1365313X.2010.04433.x

35. Semblat, J. P., Rosso, M. N., Hussey, R. S., Abad, P., and CastagnoneSereno, P. 2001. Molecular cloning of a cDNA encoding an amphid- 
secreted putative avirulence protein from the root-knot nematode Meloidogyne incognita. Mol. Plant-Microbe Interact. 14:72-79.

36. Strabala, T. J., O’Donnell P, J., Smit, A. M., Ampomah-Dwamena, C., Martin, E. J., Netzler, N., Nieuwenhuizen, N. J., Quinn, B. D., Foote, H. C., and Hudson, K. R. 2006. Gain-of-function phenotypes of many CLAVATA3/ESR genes, including four new family members, correlate with tandem variations in the conserved CLAVATA3/ESR domain. Plant Physiol. 140:1331-1344. Online publication. doi:pp.105.075515

37. Tomalova, I., Iachia, C., Mulet, K., and Castagnone-Sereno, P. 2012. The map-1 gene family in root-knot nematodes, Meloidogyne spp.: a set of taxonomically restricted genes specific to clonal species. PLoS One 7:e38656. Online publication. doi:10.1371/journal.pone.0038656

38. Tucker, M. L., and Yang, R. 2013. A gene encoding a peptide with similarity to the plant IDA signaling peptide (AtIDA) is expressed most abundantly in the root-knot nematode (Meloidogyne incognita) soon after root infection. Exp. Parasitol. 134:165-170. Online publication. doi: 10.1016/j.exppara.2013.03.019

39. Vieira, P., Danchin, E. G., Neveu, C., Crozat, C., Jaubert, S., Hussey, R. S., Engler, G., Abad, P., de Almeida-Engler, J., Castagnone-Sereno, P., and Rosso, M. N. 2011. The plant apoplasm is an important recipient compartment for nematode secreted proteins. J. Exp. Bot. 62:1241-1253. Online publication. doi:10.1093/jxb/erq352

40. Wang, J., Replogle, A., Hussey, R., Baum, T., Wang, X., Davis, E. L., and
Mitchum, M. G. 2011. Identification of potential host plant mimics of CLAVATA3/ESR (CLE)-like peptides from the plant-parasitic nematode Heterodera schachtii. Mol. Plant Pathol. 12:177-186. Online publication. doi:10.1111/j.1364-3703.2010.00660.x

41. Wang, J. Y., Lee, C., Replogle, A., Joshi, S., Korkin, D., Hussey, R., Baum, T. J., Davis, E. L., Wang, X. H., and Mitchum, M. G. 2010. Dual roles for the variable domain in protein trafficking and host-specific recognition of Heterodera glycines CLE effector proteins. New. Phytol. 187: 1003-1017. Online publication. doi:10.1111/J.1469-8137.2010.03300.X

42. Wang, X., Allen, R., Ding, X., Goellner, M., Maier, T., de Boer, J. M., Baum, T. J., Hussey, R. S., and Davis, E. L. 2001. Signal peptideselection of cDNA cloned directly from the esophageal gland cells of the soybean cyst nematode Heterodera glycines. Mol. Plant-Microbe Interact. 14:536-544. Online publication. doi:10.1094/MPMI.2001.14.4.536

43. Wang, X., Mitchum, M. G., Gao, B., Li, C., Diab, H., Baum, T. J., Hussey, R. S., and Davis, E. L. 2005. A parasitism gene from a plantparasitic nematode with function similar to CLAVATA3/ESR (CLE) of Arabidopsis thaliana. Mol. Plant Pathol. 6:187-191. Online publication. doi:10.1111/j.1364-3703.2005.00270.x

44. Whitford, R., Fernandez, A., De Groodt, R., Ortega, E., and Hilson, P. 2008. Plant CLE peptides from two distinct functional classes synergistically induce division of vascular cells. Proc. Natl. Acad. Sci. USA 105:18625-18630. Online publication. doi:10.1073/Pnas.0809395105 